\title{
Characteristics of the Work Environment of Magnet Hospitals and Job Satisfaction among Nurses in Japan: A Cross-Sectional Study Using Multi- Level Analysis
}

Maki Tei-Tominaga ${ }^{1 *}$, Masao Tsuchiya ${ }^{2}$ and Fusako Sato ${ }^{3}$

${ }^{1}$ Department of Nursing, Hyogo University of Health Sciences, Japan

${ }^{2}$ National Institute of Occupational Safety and Health, Japan

${ }^{3}$ College of Nursing, Aichi Medical University, Nagakute, Aichi, Japan

\begin{abstract}
Background: The Magnet hospital is a recognition system in the US having a low turnover and high retention of nurses and providing a high quality of patient care. We sought to examine the effect of characteristics of the work environment of Magnet hospitals on nurses' job satisfaction using multi-level analysis in hospitals in Japan.

Methods: We distributed anonymous self-administered questionnaires in August 2011 to all nurses via the directors of the nursing departments of four private hospitals. The response rate of nurses was $91 \%$; 373 completed questionnaires in 21 wards were used for analysis. The questionnaire items addressed basic attributes and employment characteristics, the Japanese version of the Practice Environment Scale of the Nursing Work Index (PES-NWI) for assessing characteristics of the work environment of Magnet hospitals, and a job satisfaction scale. We conducted multi-level analysis to examine effects of the PES-NWI sub-scales at both the individual and ward levels on nurses' job satisfaction.
\end{abstract}

Results: Results of the multi-level analysis for nurses' job satisfaction showed that a full model which included the sub-scales of the PES-NWI at both the individual and ward levels was the most appropriate model. Additionally, coefficients of ward-level values showing significant relationships with job satisfaction were greater than those of individual-level values. At the individual level, all sub-scales of the PES-NWI except for "nurse participation in hospital affairs" showed positive relationships with nurses' job satisfaction, while at the ward level "nurse participation in hospital affairs" showed a significant positive relationship, and "nurse manager ability, leadership, and support of nurses" showed a significant negative relationship, with nurses' job satisfaction.

Conclusion: These findings suggest that while characteristics of the work environment of Magnet hospitals are important predictors, factors relating to cultural differences, such as decentralized department structures, might influence nurses' job satisfaction at the ward level.

Keywords: Practice environment scale of the nursing work index; Job satisfaction; Multi-level analysis

\section{Introduction}

Japan has the highest life expectancy in the world, resulting in a rapidly growing and aging society [1]. Growth in this aging society results in a higher demand for a greater amount of higher quality health services, including that of nurses. The Ministry of Health, Labour and Welfare in Japan estimates that the demand for nurses is outstripping the supply, and that this will continue until at least 2015 [2].

The retention of nurses is essential for the future supply of nurses to be able to sustain high quality patient care. Additionally, in Japan nurses need more than 5 years' work experience to become expert nurses in a specific area (such as becoming a certified nurse, clinical nurse specialist) [3]. In this context, the approach to sustaining high quality patient care and the retention of nurses in hospitals/facilities with Magnet recognition is noteworthy [4].

In 1994, the American Nurses Credentialing Center established the designation of Magnet recognition. This system recognizes Magnet hospitals as those that have sustained a low turnover and high retention of nurses and have provided a high quality of patient care $[4,5]$. The recognition of Magnet hospitals has been expanding in the United States and internationally. There are 395 Magnet hospitals in the world at present (November $1^{\text {st }}$ 2012) [6]. The Magnet hospital recognition system has also attracted the attention of hospital administrators and researchers in Japan [7-10].

Researchers have revealed the advantages of Magnet hospitals over
non-Magnet hospitals based on empirical studies. Previous studies have compared the differences between Magnet hospitals and non-Magnet hospitals, and revealed the superiorities of Magnet hospitals based on outcomes related to nurses and patients (such as job satisfaction of nurses, intention to leave, nurses' perceptions of care quality or safety, patient satisfaction) [11-13]. Additionally, characteristics of the work environment of Magnet hospitals have been shown to influence nurses' job satisfaction/dissatisfaction [11-14], burnout [14], and turnover [13], highlighting the significance of the work environment of Magnet hospitals.

Although no hospitals have yet applied for Magnet recognition in Japan, two studies $[9,10]$ have examined the effect of characteristics of the work environment of Magnet hospitals on nurses' job satisfaction and the intention to stay, using the Japanese version of the Practice Environment Scale of the Nursing Work Index (PES-NWI) [8]

*Corresponding author: Maki Tei-Tominaga, Department of Nursing, Hyogo University of Health Sciences, 1-3-6 Minatojima, Chuo-ku, Kobe 650-8530, Japan Tel: +81-78-304-3063; Fax: +81-78-304-2763; E-mail: temakimaki@huhs.ac.jp

Received November 01, 2012; Accepted November 24, 2012; Published November 28, 2012

Citation: Tominaga MT, Tsuchiya M, Sato F (2012) Characteristics of the Work Environment of Magnet Hospitals and Job Satisfaction among Nurses in Japan: A Cross-Sectional Study Using Multi-Level Analysis. J Nurs Care S5:003. doi:10.4172/2167-1168.S5-003

Copyright: (C) 2012 Tominaga MT, et al. This is an open-access article distributed under the terms of the Creative Commons Attribution License, which permits unrestricted use, distribution, and reproduction in any medium, provided the original author and source are credited. 
developed by Lake [15]. The studies' findings [9,10] revealed that all correlation coefficients between the PES-NWI sub-scales and job satisfaction were significant $(\mathrm{P}<0.01)$, and nurses who received a higher PES-NWI score showed higher intention to stay. This suggests the importance of characteristics of the work environment of Magnet hospitals on nurses' job satisfaction and retention.

However, a study noted that the failure to use a hierarchical model of analysis results in a misestimation of the relationship between nursing workforce characteristics and outcomes. Dunton et al. [16] indicated that when multi-level techniques are not applied to the analysis of data that represent patients embedded in units and units embedded in hospitals, researchers can wrongly specify relationships. If a hospital's work environment shows the characteristics of a Magnet hospital, the characteristics of the work environment of each ward should be observed.

In this context, multi-level modeling identifying each unit's characteristics as specified by the PES-NWI is particularly important for the analysis of characteristics of the work environment of Magnet hospitals [5]. Cho [17] indicated that multi-level modeling allows researchers to simultaneously examine the relationship of variables at the individual and group levels.

Multi-level analysis using formulated multi-level modeling has several advantages over conventional statistical techniques. First, data from more than one hierarchical level can be included in the same analysis. Second, the statistical dependence among individuals of the same ward is taken into account through random variation across departments. Finally, multi-level modeling separates sampling errors due to variation among departments from variation within departments [18].

To emulate the approach of Magnet hospitals in the areas of nurses' job satisfaction and retention in Japan, an empirical study which examines the effect of characteristics of the work environment of Magnet hospitals at both the individual and ward levels using analysis for multi-level modeling (that is, a multi-level analysis) is required. Thus, the purpose of this study was to examine the effect of characteristics of the work environment of Magnet hospitals on nurses' job satisfaction using multi-level analysis in hospitals in Japan.

\section{Materials and Methods}

\section{Ethical considerations}

Approval for this study was obtained from the institutional ethics committee at the Hyogo University of Health Sciences (\#10028) in 2011. All nurses in this survey were not required to sign consent forms as return of the questionnaire constituted implied consent. Participants were informed about the voluntary nature of participation and assured of confidentiality in the handling of data.

\section{Participants and data collection}

Four private hospitals agreed to cooperate with the survey, and returned consent forms signed by the hospitals' directors after a researcher's explanation. Three of the hospitals were general hospitals and one was a hospital for mainly long-term nursing care and medical treatment. Turnover at the four hospitals ranged from $7.8-20 \%$. The number of beds of the four hospitals was from 50-350 (Table 1).

In August 2011, we distributed a questionnaire to all nurses $(\mathrm{N}=469)$ in all wards $(\mathrm{N}=21)$ of the four hospitals. The person in charge of the nursing department in each hospital provided information about the study to potential participants. If nurses agreed to participate, they completed and returned their questionnaire to the researcher in a sealed envelope within 1-4 weeks of distribution. No reminder was sent to the participants after the first notice of the study.

Four hundred twenty-five nurses (91\%) returned their completed questionnaires. Response rates of 21 wards in 4 hospitals ranged from $70-100 \%$. After eliminating incomplete data, including missing or incomplete answers $(\mathrm{N}=52)$, we used the set of completed questionnaires $(\mathrm{N}=373)$ of the 21 wards for analysis. Ninety-six percent $(\mathrm{N}=359)$ of participants were female. Females were aged an average of $34.64(\mathrm{SD}=8.89)$ years, and males an average of $28.86(\mathrm{SD}=5.55)$ years.

\section{Measures}

The questionnaire items addressed basic attributes (sex, age, marital status, educational level), and employment characteristics (working hours, frequency of working on days off per month, working tenure) as control variables; a scale of characteristics of the work environment of Magnet hospitals (the Japanese version of the PES-NWI) as independent variables; and a job satisfaction scale as a dependent variable.

\section{The practice environment scale of the nursing work index (PES-NWI)}

To assess characteristics of the work environment of Magnet hospitals, we used the 31 items of the Japanese version of the (PESNWI) [8] developed by Lake [15]. The Japanese version of the PESNWI was developed by the translation and back-translation procedure, and comprises five sub-scales: nurse participation in hospital affairs (nine items, for example, "Staff nurses are involved in the internal governance of the hospital"), nursing foundations for quality of care (ten items, for example, "Use of nursing diagnoses"), nurse manager ability, leadership, and support of nurses (five items, for example, "A head nurse who is a good manager and leader"), staffing and resource adequacy (four items, for example, "Enough staff to get the work done"), and collegial nurse-physician relations (three items, for example, "A lot of teamwork between nurses and doctors") $[8,15]$. The PES-NWI has demonstrated internal consistency and content validity with high reliability for nurses [15], including Japanese nurses $[9,10]$. The questions have four response options: "totally disagree", "disagree", "agree", "totally agree", with each item scored using a Likert scale (1-4). The average scores of each sub-scale were calculated and used. Higher total scores indicated more characteristics of the work environment of Magnet hospitals, meaning a desirable practice environment.

\section{Job satisfaction}

Job satisfaction of nurses was assessed by a Japanese translation

\begin{tabular}{|l|l|l|l|l|l|l|}
\hline Hospital & Number of Beds & Number of Nurses & Number of wards & $\begin{array}{l}\text { Turnover ratio } \\
\text { of nurses }\end{array}$ & $\begin{array}{l}\text { Vacancy rate of } \\
\text { Nurses }\end{array}$ & Type of shift \\
\hline Hospital A & 349 & 196 & 8 & $14.2 \%$ & $94 \%$ & $\begin{array}{l}\text { Ratio of the number of } \\
\text { patients to that of nurses }\end{array}$ \\
\hline Hospital B & 279 & 160 & 6 & $9.0 \%$ & $100 \%$ & 2 -shift system \\
\hline Hospital C & 154 & 95 & 5 & $7.8 \%$ & $100 \%$ & 2 -shift system \\
\hline Hospital D & 72 & 17 & 2 & $20.0 \%$ & $93 \%$ & 2 -shift system \\
\hline
\end{tabular}

Table 1: Characteristics of hospitals $(\mathrm{N}=4)$. 
Citation: Tominaga MT, Tsuchiya M, Sato F (2012) Characteristics of the Work Environment of Magnet Hospitals and Job Satisfaction among Nurses in Japan: A Cross-Sectional Study Using Multi-Level Analysis. J Nurs Care S5:003. doi:10.4172/2167-1168.S5-003

Page 3 of 6

[19] of a 15-item scale originally developed by McLean [20], which demonstrated high internal consistency and reliability in Japanese workers [19,21-23]. The scale measures the degree of job satisfaction with regard to various working conditions (such as human relationships, remuneration, and career opportunity). The questions have five response options: "very satisfied", "satisfied", "neutral", "dissatisfied", "very dissatisfied", with each item scored using a Likert scale (1-5) [23]. The higher the total score, the greater the satisfaction perceived by participants.

Concerning organizational characteristics, such as hospital size and type, basic charge for hospitalization, and section of organization (for example, ward), we matched both the individual data of nurses and patients with their organizational data.

\section{Analysis}

We calculated descriptive statistics and Cronbach alphas of the subscales of the PES-NWI and the job satisfaction scale. We also calculated correlation coefficients among the job satisfaction score and each dependent variable.

$\mathrm{Wu}$ and Wooldridge [24] indicated that one of the issues analysts should be familiar with is the appropriate use of centering techniques in transforming raw scores into deviation form by subtracting the grand mean. Mean centering a predictor variable makes the intercept interpretable as the value of the response variable at the mean value of the predictor variable. It can help with avoiding collinearity among predictors. In fixed coefficient regression analysis (such as multi-level analysis), grandmean centering is often desirable, and its consequences are understood. Thus, as preliminary multi-level analysis, we centered each individual subscale value of the PES-NWI by the average values of all sub-scales of the PES-NWI. Similarly, we centered each ward-level value of the PES-NWI sub-scales by the average values of all sub-scales of the PES-NWI.

\begin{tabular}{|c|c|c|c|}
\hline \multicolumn{2}{|c|}{ Variables } & $\mathbf{N}$ & $\%$ \\
\hline \multicolumn{4}{|c|}{ Individual Attributes } \\
\hline \multirow[t]{2}{*}{ 1. Sex } & Female & 359 & 96 \\
\hline & Male & 14 & 4 \\
\hline \multirow[t]{2}{*}{ 2. Marital Status } & Single & 136 & 35 \\
\hline & Married & 237 & 64 \\
\hline \multirow[t]{2}{*}{ 3. Education } & Junior college or vocational school equivalency Degree & 357 & 96 \\
\hline & College graduate or higher & 16 & 4 \\
\hline \multicolumn{4}{|c|}{ Organizational and employment characteristics } \\
\hline \multirow[t]{4}{*}{ 4. Organization } & Hospital A & 149 & 40 \\
\hline & Hospital B & 127 & 34 \\
\hline & Hospital C & 86 & 23 \\
\hline & Hospital D & 11 & 3 \\
\hline \multirow{6}{*}{$\begin{array}{l}\text { 5. Average } \\
\text { Working hours } \\
\text { per week }\end{array}$} & $\leq 40 \mathrm{H}$ & 50 & 13 \\
\hline & $41-44 \mathrm{H}$ & 142 & 49 \\
\hline & $45-49 \mathrm{H}$ & 83 & 22 \\
\hline & $50-54 \mathrm{H}$ & 36 & 10 \\
\hline & $55-59 \mathrm{H}$ & 13 & 3 \\
\hline & $\geq 60 \mathrm{H}$ & 9 & 2 \\
\hline \multirow{4}{*}{$\begin{array}{l}\text { 6. Frequency of } \\
\text { working on days } \\
\text { off per month }\end{array}$} & None & 264 & 71 \\
\hline & One or two days per month & 63 & 17 \\
\hline & Three to four days per month & 30 & 8 \\
\hline & Five or more days per month & 16 & 4 \\
\hline \multicolumn{2}{|l|}{ 7. Working tenure } & \multicolumn{2}{|c|}{$4.45 \pm 5.20$} \\
\hline
\end{tabular}

Table 2: Basic attributes, employment and organizational characteristics of nurses $(\mathrm{N}=373)$.

\begin{tabular}{|l|l|l|l|l|l|l|}
\hline Variables & Mean & SD & \multicolumn{1}{l|}{ Items } & Range & Cronbach's Alphas \\
\hline $\begin{array}{l}\text { The Japanese version of the PES-NWI } \\
\begin{array}{l}\text { Nurse Participation in } \\
\text { Hospital Affairs }\end{array}\end{array} 2.50$ & 0.41 & 9 & $1-4$ & 0.782 \\
\hline $\begin{array}{l}\text { Nursing Foundation for } \\
\text { Quality of Care }\end{array}$ & 2.54 & 0.41 & 10 & $1-4$ & 0.831 \\
\hline $\begin{array}{l}\text { Nurse manager ability, } \\
\text { Leadership and Support of } \\
\text { Nurses }\end{array}$ & 2.68 & 0.57 & 5 & $1-4$ & 0.856 \\
\hline $\begin{array}{l}\text { Staffing and Resource } \\
\text { Adequacy }\end{array}$ & 2.39 & 0.59 & 4 & $1-4$ & 0.800 \\
\hline $\begin{array}{l}\text { Collegial Nurse-Physician } \\
\text { Relations }\end{array}$ & 2.45 & 0.53 & 3 & $1-4$ & 0.806 \\
\hline Job Satisfaction & 46.01 & 11.16 & 15 & $15-75$ & 0.934 \\
\hline
\end{tabular}

Table 3: Descriptive statistics and Cronbach's Alphas of independent and depandant variables among nurses $(\mathrm{N}=373)$.

\begin{tabular}{|c|c|c|c|c|c|c|}
\hline & (1) & (2) & (3) & (4) & (5) & (6) \\
\hline $\begin{array}{l}\text { 1. Nurse Participation in } \\
\text { Hospital Affairs }^{\mathrm{a}}\end{array}$ & 1 & & & & & \\
\hline $\begin{array}{l}\text { 2. Nursing Foundation for } \\
\text { Quality of Care }\end{array}$ & $0.757^{* * *}$ & 1 & & & & \\
\hline $\begin{array}{l}\text { 3. Nurse manager ability, } \\
\text { Leadership and Support of } \text { Nurses }^{\mathrm{a}}\end{array}$ & $0.638^{* * *}$ & $0.596^{* * *}$ & 1 & & & \\
\hline $\begin{array}{l}\text { 4. Staffing and Resource } \\
\text { Adequacy }^{a}\end{array}$ & $0.426^{* * *}$ & $0.356^{* * *}$ & $0.375^{* * *}$ & 1 & & \\
\hline $\begin{array}{l}\text { 5. Collegial Nurse-Physician } \\
\text { Relations }^{a}\end{array}$ & $0.542^{* * *}$ & $0.597^{* * *}$ & $0.406^{* * *}$ & $0.345^{* * *}$ & 1 & \\
\hline 6. Job Satisfaction & $0.582^{* * *}$ & $0.571^{* * *}$ & $0.518^{* * *}$ & $0.545^{* * *}$ & $0.490^{* * *}$ & 1 \\
\hline
\end{tabular}

Symbol indicates level of significance: ${ }^{* * *} p<0.001$

aThe Japanese version of the PES-NWI

Table 4: Pearson correlation coefficients between sub-scales of the PES-NWI and job satisfaction $(\mathrm{N}=373)$.

We then conducted multi-level analysis to formulate and examine the relationship between nurses' job satisfaction and the PES-NWI at two levels (individual and ward) in which Magnet hospitals should be observed. First, for nurses' job satisfaction, individual-level variables of the PES-NWI were added into an equation as independent variables controlling for sex, age, marital status, frequency of working on days off per month, and working hours (model 1). Next, ward-level variables of the PES-NWI were added into the equation (model 2). Finally, both individual-level and ward-level variables of the PES-NWI were added into the equation (model 3). We performed statistical analyses with SPSS 15.0 (IBM, Tokyo, Japan). The multi-level analyses were estimated using the computer program STATA 12.0 (StataCorp LP, College Station, Texas, USA). A P-value of less than 0.05 was regarded as indicating statistical significance.

\section{Results}

Table 2 shows a summary of basic attributes and employment and organizational characteristics of the participants. Ninety-six percent of participants had a junior college or vocational school equivalency degree in nursing, and $64 \%$ were married. Fifteen percent of participants worked more than 50 hours a week, which entailed more than 40 hours of overtime work on a monthly basis.

As shown in table 3 , alpha coefficients of sub-scales of the PES-NWI were from $0.78-0.86$, and that of the job satisfaction score was 0.93 . The results of Pearson correlation coefficients between the PES-NWI sub-scales and a job satisfaction score (Table 4) were from 0.490-0.582 $(\mathrm{P}<0.001)$. The highest correlation coefficient for the job satisfaction score was for "staffing and resource adequacy" $(\mathrm{r}=0.512, \mathrm{P}<0.001)$. 
Citation: Tominaga MT, Tsuchiya M, Sato F (2012) Characteristics of the Work Environment of Magnet Hospitals and Job Satisfaction among Nurses in Japan: A Cross-Sectional Study Using Multi-Level Analysis. J Nurs Care S5:003. doi:10.4172/2167-1168.S5-003

Page 4 of 6

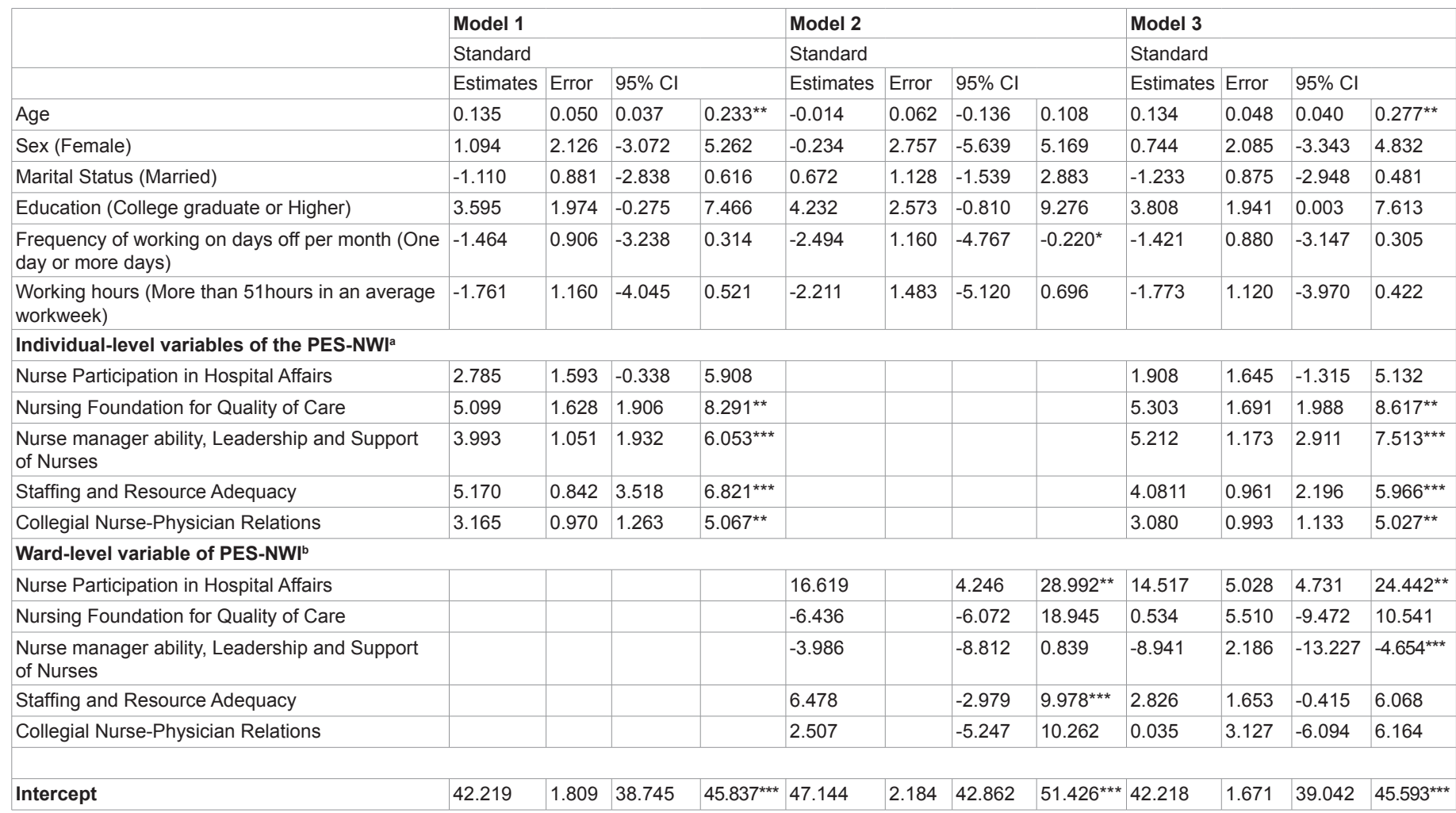

Symbol indicates level of significance: ${ }^{*} p<0.05,{ }^{* *} p<0.01^{* * *}, p<0.001$

a We centred each individual subscale of PES-NWI value by the average values of all sub-scales of the PES-NWI.

${ }^{b}$ We centred each Ward level values of PES-NWI sub-scales by the average values of all sub-scales of the PES-NWI.

Table 5: Results of coefficient estimates form the multi level analysis in the job satisfaction among nurses (N-373)

Table 5 showed the results of the multi-level analysis for job satisfaction. Model 3, in which both individual-level and ward-level values of the PES-NWI were entered into the equation, showed the lowest log likelihood score (log likelihood=-1277.15), compared with single linear models (model 1 (-1287.206) and model $2(-1383.174)$ ) in which either individual-level or ward-level PES-NWI scores were entered into the equations. This indicated that model 3 was the most appropriate model.

In model 1, individual-level values of all sub-scales of the PESNWI, except for "nurse participation in hospital affairs", showed significant positive relationships with job satisfaction. In model 2, ward-level values of "nurse participation in hospital affairs" $(\mathrm{P}<0.01)$ and "staffing and resource adequacy" $(\mathrm{P}<0.001)$ showed significant positive relationships with job satisfaction. In model 3, individual-level values of all sub-scales of the PES-NWI except for "nurse participation in hospital affairs" showed significant positive relationships with job satisfaction, while forward-level values "nurse participation in hospital affairs" showed a significant positive relationship $(\mathrm{P}<0.01)$, and "nurse manager ability, leadership, and support of nurses" $(\mathrm{P}<0.001)$ showed a significant negative relationship with job satisfaction.

\section{Discussion}

Dunton et al. [16] highlighted the benefit of multi-level techniques for analysis of data representing individuals (such as patients) embedded in units and units embedded in hospitals. Harless and Mark [25] demonstrated that relationships in many previous research studies might have been attenuated by having access only to hospital-level nurse staffing data and not unit-level data. In the present study, we examined the effect of characteristics of the work environment of Magnet hospitals on nurses' job satisfaction using multi-level analysis. We found that model 3 (that is, an equation into which we entered the sub-scales of the PES-NWI at both the individual and ward level) was the most appropriate model. Our findings support previous studies' findings on the significance of characteristics of the work environment of Magnet hospitals on nurses' job satisfaction/dissatisfaction in individual-level values of the PES-NWI [10-12,14], and add new insights.

It should be noted that coefficients of ward-level values which showed significant relationships with job satisfaction (for example, "nurse participation in hospital affairs", "nurse manager ability, leadership, and support of nurses") were greater than those of individual-level values in this study. This might suggest that the characteristics of the work environment of Magnet hospitals as perceived at the ward level are more influential on nurses' job satisfaction than those perceived at the individual level.

We also found that the PES-NWI sub-scales which showed significant relationships with nurses' job satisfaction were inconsistent between individual-level and ward-level values. At the individual level, all PES-NWI sub-scales showed significant relationships with nurses' job satisfaction except for one sub-scale. This sub-scale, "nurse participation in hospital affairs", showed a significant positive relationship with nurses' job satisfaction at the ward level. These findings suggest that hospital employers need to evaluate nurses' performance (such as nurse participation in hospital affairs) at the ward level to improve nurses' job satisfaction.

At the ward level, however, the PES-NWI sub-scale "nurse manager ability, leadership, and support of nurses", showed a significant negative relationship with nurses' job satisfaction. This result was inconsistent with previous findings that show a significantly positive relationship 
Citation: Tominaga MT, Tsuchiya M, Sato F (2012) Characteristics of the Work Environment of Magnet Hospitals and Job Satisfaction among Nurses in Japan: A Cross-Sectional Study Using Multi-Level Analysis. J Nurs Care S5:003. doi:10.4172/2167-1168.S5-003

Page 5 of 6

among sub-scales of characteristics of the work environment of Magnet hospitals and nurses' job satisfaction [10,26]. These findings suggest that perception of a manager's performance (such as nurse manager ability, leadership, and support of nurses) among nurses at the ward level is different from that at the individual level. The discrepancy among the individual-level and ward-level values of the PES-NWI sub-scales may reflect unmeasured confounders, such as cultural differences among individual nurses and ward-level nurses.

A study of Magnet hospitals $(\mathrm{N}=41)$ in the United States reported that the leadership of nurse managers was the key to success in recruiting and retaining nurses [27]. However, a case study revealed that when recruiting a new nursing manager, a Japanese hospital followed a closed recruitment system in which candidates were chosen without clear requirements for the job position, while United States Magnet hospitals also examined by the study followed an open recruitment system that was objective, transparent, and fair [28].

This study also revealed that in the Magnet hospitals, nursing managers and staff nurses in each ward recognized their own responsibilities and provided leadership based on considerable discretion given by their organization. However, these circumstances were not observed in nursing managers or nurses at the ward level in the Japanese hospital which kept a low turnover of nurses, while both Magnet hospitals and the Japanese hospital took measures for keeping nurses' lives balanced between work and private life [28].

Decentralized department structures in Magnet hospitals create a sense of control over the immediate work environment at the nursing unit level, including opportunities to plan the budget and experiment with innovative staffing patterns [27]. The Japanese hospital in the case study kept a low turnover of nurses even though it did not use decentralized department structures [28]. This might have influenced the significant negative relationship between ward-level nurses' job satisfaction and "nurse manager ability, leadership, and support of nurses" in this study.

The present study has some limitations that should be discussed. First, participants were nurses of 21 wards in 4 private general hospitals, making the results possibly unique to the participants in this study. Additionally, the number of wards was relatively small for multilevel analysis. A study using a larger sample and multi-level analysis is needed in the future. Second, as this study used a cross-sectional design, longitudinal surveys are needed to determine the causal relationships among characteristics of the work environment and nurses' job satisfaction. Third, the reliability and validity of the Japanese version of the PES-NWI should be validated in future studies. Fourth, further studies of nurses' job satisfaction are encouraged to examine the relationships among nurses' job satisfaction and characteristics of the work environment of Magnet hospitals, including factors relating to cultural differences (such as decentralized department structures) given that the Magnet hospital recognition system originated in the United States.

Researchers have emphasized the importance of nurses' job satisfaction on their intention to leave because it shows greater significance than other predictors such as age, working evening shifts, and career advancement [29-32]. Additionally, there is no study which examines the relationship between characteristics of the work environment of Magnet hospitals and nurses' job satisfaction using multi-level analysis in Japan. Thus, although our study has some limitations, our findings provide meaningful new insights for hospital employers and nursing managers to improve the retention of nurses.

\section{Conclusions}

This study examined the effect of characteristics of the work environment of Magnet hospitals on nurses' job satisfaction using multi-level analysis in hospitals in Japan. The results are summarized as follows:

1. We revealed that a full model (that is, an equation into which was entered the sub-scales of the PES-NWI at both the individual and ward levels) is the most appropriate model.

2. Coefficients of ward-level values which showed significant relationships with job satisfaction (such as "nurse participation in hospital affairs", "nurse manager ability, leadership, and support of nurses") were greater than those of individual-level values.

3. At the individual level, all sub-scales of the PES-NWI except for "nurse participation in hospital affairs" showed positive relationships with the nurses' job satisfaction, while forwardlevel values, "nurse participation in hospital affairs" showed a significant positive relationship, and "nurse manager ability, leadership, and support of nurses" showed a significant negative relationship with job satisfaction.

\section{Acknowledgments}

This study was supported by a Grant-in-Aid for Scientific Research from the Ministry of Labour and Welfare, Japan, in 2011.

\section{References}

1. Health Labour and Welfare Statistics Association (2011) The second section Major index of hygiene: trend of population, Okumura printing company, Tokyo Japan

2. Ministry of Health Labour and Welfare (2010) The seventh result of the study concerning the supply-demand outlook of nursing staff. Ministry of Health, Labour and Welfare, Health Policy Bureau, Tokyo, Japan.

3. Sato N (1999) The current status of systems for professional nursing Igakusyoin, Tokyo, Japan.

4. American Nurses Credentialing Center (2012) History of the Magnet Program.

5. Drenkard K, Wolf GA, Morgan SH (2010) Magnet: The next generation: nurses making the difference. American nurses credentialing center, Silver Spring Maryland, USA.

6. American Nurses Credentialing Center (2012) Find a Magnet Hospital.

7. Kuwahara M (2008) Introduction of magnet hospital: for developing hospitals attract nurses just like a magnet. Life support company, Tokyo, Japan.

8. Ogata Y, Nagano M, Akanuma T (2008) Translating "The Practice Environment Scale of the Nursing Work Index (PES-NWI)"into Japanese. Bulleten of Chiba University School of Nursing 30: 19-24.

9. Ogata Y, Nagano M, Fukuda T, Hashimoto M (2011) Job retention and nursing practice environment of hospital nurses in Japan applying the Japanese version of the Practice Environment Scale of the Nursing Work Index (PESNWI). Nihon Koshu Eisei Zasshi 58: 409-419.

10. Ogata Y, Nagano M, Nishioka M, Akanuma T, Uchida A, et al. (2010) Preliminary study of the reliability and validity on the practice environment scale of the Nursing Work Index, PES-NWI. Nihon Iryo Byouin Kanri Gakkaishi 47: 69-80.

11. Lacey SR, Cox KS, Lorfing KC, Teasley SL, Carroll CA, et al. (2007) Nursing support, workload, and intent to stay in Magnet, Magnet-aspiring, and nonMagnet hospitals. J Nurs Adm 37: 199-205.

12. Schmalenberg C, Kramer M (2008) Essentials of a productive nurse work environment. Nurs Res 57: 2-13.

13. Ulrich BT, Buerhaus PI, Donelan K, Norman L, Dittus R (2007) Magnet status and registered nurse views of the work environment and nursing as a career. J Nurs Adm 37: 212-220.

14. Kelly LA, McHugh MD, Aiken LH (2011) Nurse outcomes in Magnet $\circledast$ and nonmagnet hospitals. J Nurs Adm 41: 428-433. 
Citation: Tominaga MT, Tsuchiya M, Sato F (2012) Characteristics of the Work Environment of Magnet Hospitals and Job Satisfaction among Nurses in Japan: A Cross-Sectional Study Using Multi-Level Analysis. J Nurs Care S5:003. doi:10.4172/2167-1168.S5-003

15. Lake ET (2002) Development of the practice environment scale of the Nursing Work Index. Res Nurs Health 25: 176-188.

16. Dunton N, Gajewski B, Klaus S, Pierson B (2007) The Relationship of Nursing Workforce Characteristics to Patient Outcomes. The Online Journal of Issues of Nursing 12.

17. Cho SH (2003) Using multilevel analysis in patient and organizational outcomes research. Nurs Res 52: 61-65.

18. van Veldhoven M, de Jonge J, Broersen S, Kompier M, Meijman T (2002) Specific relationships between psychosocial job conditions and job-related stress: A three-level analytic approach. Work and Stress: An International Journal of Work, Health and Organisations 16: 207-228.

19. Iwata N, Suzuki K, Saito K, Abe K (1992) Type A personality, work stress and psychological distress in Japanese adult employees. Stress Med 8: 11-21.

20. McLean AA (1979) Work Stress, Addison-Wesley, Boston.

21. Tei M, Yamazaki Y (2003) The impact of work and organizational characteristics on the health status, job dissatisfaction and turnover intentions of workers in an information service industry. Sangyo Eiseigaku Zasshi 45: 20-30.

22. Tominaga M, Asakura T, Akiyama $T$ (2007) The effect of micro and macro stressors in the work environment on computer professionals' subjective health status and productive behavior in Japan. Ind Health 45: 474-486.

23. Tanaka M (1997) A study on the factors of job satisfacrtion and its scale. Waseda Psychological Reports 30: 29-36.

24. Wu YW, Wooldridge PJ (2005) The impact of centering first-level predictors on individual and contextual effects in multilevel data analysis. Nurs Res 54 212-216.

25. Harless DW, Mark BA (2006) Addressing measurement error bias in nurse staffing research. Health Serv Res 41: 2006-2024.

26. Spence Laschinger HK (2008) Effect of empowerment on professional practice environments, work satisfaction, and patient care quality: further testing the Nursing Worklife Model. J Nurs Care Qual 23: 322-330.

27. McClure M, Pulin M, Sovie M, Wandelt M (2002) Mangnet hospitals: attraction and retention of professional nurses, in Magnet hospitals revisited. American Nurses Association.

28. Tominaga M, Sato F, Michiwaki M (2012) Cross-cultural study concerning leadership and management style of nursing managers: a case study of magnet hospitals in the U.S. and a Japanese hospital. Psyche and Culture 11: 169-184

29. Zurmehly J, Martin PA, Fitzpatrick JJ (2009) Registered nurse empowerment and intent to leave current position and/or profession. J Nurs Manag 17: 383 391

30. Ma JC, Lee PH, Yang YC, Chang WY (2009) Predicting factors related to nurses' intention to leave, job satisfaction, and perception of quality of care in acute care hospitals. Nurs Econ 27: 178-184.

31. Applebaum D, Fowler S, Fiedler N, Osinubi O, Robson M (2010) The impact of environmental factors on nursing stress, job satisfaction, and turnover intention. J Nurs Adm 40: 323-328.

32. Hayes LJ, O'Brien-Pallas L, Duffield C, Shamian J, Buchan J, et al. (2012) Nurse turnover: A literature review-An update. Int J Nurs Stud 49: 887-905. 